\title{
Las autopromociones desde el punto de vista de la continuidad y la comunicación publicitaria en televisión
}

\author{
Javier PÉREZ SÁNCHEZ \\ Universidad Europea de Madrid \\ javier.perez@uem.es
}

Recibido: $10 / 07 / 2012$

Aceptado: 30/10/2012

\section{Resumen}

Las autopromociones hoy día se han convertido en piezas con entidad propia y de gran importancia dentro de las parrillas de programación de las cadenas. No solo por ser enlaces y mantener la línea de la continuidad visual de los contenidos televisivos, sino también por es un arma de Comunicación publicitaria de los canales para convencer a los espectadores. Por estas razones es importante establecer las diferencias y las similitudes comunes de las promociones televisivas, tanto desde el punto de vista de la continuidad como de la comunicación publicitaria, para poder posteriormente insertarlas en la docencia universitaria como herramienta de innovación docente en cuanto a contenidos se refiere.

Palabras clave: Autopromoción, promoción, televisión, continuidad y comunicación publicitaria.

\section{The self-promotions from the point of view of continuity and advertising in television}

\begin{abstract}
:
The self-promotions today have become pieces with its own entity and of great importance within the program schedules of the chains. Not only for being links and maintain the visual continuity of the television content but also because it is a weapon of advertising communication of the channels to convince viewers. For these reasons it is important to establish the differences and common similarities of television promotions, both from the point of view of continuity and of the advertising, in order to later insert them into university teaching as a tool for teaching innovation in terms of contents refers.

Keywords: Self-promotion, promotion, television, continuity, advertising.

\section{Referencia normalizada}

PÉREZ SÁNCHEZ, Javier (2012): "Las autopromociones desde el punto de vista de la continuidad y la comunicación publicitaria en televisión". Estudios sobre el mensaje periodístico. Vol. 18, núm. especial noviembre, págs.: 713-720. Madrid, Servicio de Publicaciones de la Universidad Complutense.
\end{abstract}

Sumario: 1. Introducción. 2. Metodología. 3. Autopromociones desde el punto de vista de la continuidad. 4. Autopromociones desde el punto de vista de la Comunicación publicitaria. 5. Conclusiones. 6. Referencias bibliográficas.

\section{Introducción}

Las autopromociones son en la actualidad piezas de suma importancia en todos los canales de televisión existentes en España. Todos los grupos de comunicación televisiva en nuestro país poseen su propio departamento de autopromociones, y cada vez son más esenciales a la hora de convencer al saturado espectador televisivo de ver los contenidos en un determinado canal. Las autopromociones españolas, copan un buen lugar internacionalmente en cuanto al reconocimiento de calidad y cantidad de piezas en estos últimos años. Desde nuestra investigación hemos decido abordar claramente las dos funciones principales de las promociones televisivas españolas, desde la continuidad y la Comunicación publicitaria. Y así poder incluirlas como nuevo contenido 
docente dentro de las asignaturas de Comunicación audiovisual y Publicidad, para desarrollar en los alumnos nuevas posibilidades creativas y profesionales.

\section{Metodología}

Para realizar este artículo hemos llevado distintos métodos de investigación, siempre teniendo en cuenta las escasas referencias bibliográficas explícitas a las autopromociones, y contrastando todas las fuentes posibles con la intención de llegar a unos resultados o conclusiones totalmente irrebatibles y compartidas por la mayoría de los expertos de este tema. En este artículo hemos utilizado los métodos científicos necesarios para conseguir los resultados más rigurosos, entendiendo estos "métodos" como procedimientos para tratar un conjunto de problemas que es lo que distingue y particulariza el saber científico, cuando éste es entendido en sentido estricto. Pero en cuanto al término Ciencia, obliga a delimitar que se entiende por ella, lo que entraña en sí mismo una gran dificultad; para Weinberg y su expresión "big sciencie" hay dos realidades: "por un lado la enorme amplitud de la Ciencia y por otra parte, su extraordinario crecimiento" (Weinberg, 1967: 17). Para conseguir este método científico hemos optado para dicha exposición dos vías principales, las referencias puramente bibliográficas y de artículos, y por otro lado una metodología de entrevistas a expertos sobre la materia a tratar.

\section{Autopromociones desde el punto de vista de la continuidad}

Continuidad en español corresponde a la noción inglesa de continuity, pero existe otro concepto, el de imagen de cadena (packing o embalaje, en inglés, habillage o indumentaria, en francés), que normalmente se incluye en ella, y que implica algo diferente. La continuidad entendida como imagen de cadena tiene la misión específica de dar identidad al canal. No se trata solo de dotarlo de una apariencia o una indumentaria atractiva, sino de un alma, un estilo que refleje su personalidad. Detrás de la rejilla de cada cadena se puede distinguir lo que Sarah Kozloff llama un "súper narrador" (Kozloff, 1989: 22), que se manifiesta de distintas maneras: en forma de logos, melodías, y muy importante, locutores, que bien como bustos parlantes o como voces en "off", hablan por boca de la cadena presentándola como una unidad. Cada estación utiliza estas voces o rostros que se dirigen al espectador para adelantarle la programación justificar cambios de horario o dificultades técnicas, que interrumpen el flujo para dar boletines informativos.

La carta de ajuste, la presencia y animación de logos, las reglas gráficas para la presentación de la información, las cabeceras y la escenografía de las producciones propias, los caracteres tipográficos, los códigos cromáticos, la música y el comentario sonoro, son los principales elementos de este discurso. Así mismo, entran en este segmento de continuidad, las promociones de programas y las transiciones más o menos artísticas que se colocan como almohadillas entre dichas promociones, anuncios y programas.

Las autopromociones están totalmente ligadas al departamento de continuidad, ya que hasta los propios software que se utilizan están pensados para el uso de las mismas. Ponemos por ejemplo, el uso de inserciones gráficas en la propia programación donde anuncian los programas venideros, hace relativamente poco era imposible realizar estas inserciones a no ser que fueran realizadas en postproducción en produc- 
tos previamente grabados. Otra prueba de que estas piezas están muy ligadas a continuidad es uno de sus antecedentes, los llamados "locutores de continuidad". Por último, y a modo de dato relevante, es que las promos son usadas hoy día por Televisión Española (La 1 y La 2) como elemento separador de programas, para así poder diferenciar entre un producto y otro como descanso de publicidad.

Las autopromociones, para muchos expertos, son un trabajo en conjunto con continuidad, "[...] la autopromo forma parte de la continuidad, es un trabajo en conjunto, una imagen cohesionada, es un trabajo de toda la cadena, de imagen, la autopromoción cierra de una manera o abre de una manera, es un trabajo en conjunto y que debe realizarse en conjunto, cuanto más cohesionado este eso mejor imagen nos va a dar"1. Por ello es indiscutible asociarla a este aspecto, de hecho muchos canales, como ya hemos comentado, el Departamento de Autopromociones depende directamente o indirectamente de continuidad.

Para Jaime Barroso, las autopromociones cumplen “[...] una función etimológica $\mathrm{y}$ funcional, que consisten en dotar de una cierta apariencia de homogeneidad ininterrumpida, de continuo, a lo que es por principio flujo fragmentado y constante interrumpido: la programación" (Barroso, 1996: 525). Y como expresa el propio autor, las autopromociones dentro de esa fractura programática, funcionan a modo de gancho y recordatorio sobre su oferta, y como veremos en el siguiente apartado, poseen una apelación seductora al destinatario y una coherencia discursiva, por ello son piezas de entidad propia como hablamos al principio de nuestro artículo.

Pero las autopromociones no solo se relacionan con la continuidad por ser piezas separadoras o de apoyo de la imagen de canal, sino que además se ven reforzadas y aportan a las propias técnicas de continuidad y emisión existentes. Es aquí, donde explicaremos las principales técnicas de programación que se relacionan de manera muy directa con las autopromociones, bien por cómo afectan estas piezas a la mismas técnicas o bien por cómo se programe pueden reforzar el mensaje o la efectividad de las mismas. Lógicamente no abordaremos todas las técnicas existentes de programación sino exclusivamente solas aquellas que realmente son relacionadas con el objeto de este artículo. Empezamos por la primera técnica de programación, la denominada Confrontación Directa, esta técnica se utiliza cuando se programa un contenido similar al de la competencia en su misma franja horaria, aquí las promociones juegan un papel estelar, sobre todo cuando ambos productos, el de la competencia y el nuestro son estrenos como puede ocurrir con el cine o series, en ese caso una buena promoción que destaque nuestro contenido sobre el otro puede dar una ventaja de audiencia para ganar a nuestro rival. Otra técnica de programación que afecta a las promociones es la Coexistencia complementaria, esta técnica es cuando en similares franja que nuestros rivales programamos contenidos para distinto target que el otro, en este caso las promociones deben ser muy meditadas y dirigidas a los espectadores tipo que queremos para nuestro programa, diferenciándolos así de los que sabemos que prefieren

${ }^{1}$ Entrevista a Joaquín Rodríguez Moldenhauer. Director del Departamento de Promociones de Antena 3. Realizada el 10 de Mayo de 2012. 
el contenido de nuestra competencia; suele ocurrir en promociones que anuncian ficción frente a contenidos de realidad o viceversa, aunque se puede aplicar a multitud contenidos diferenciados por su target y género. En cuanto a la estrategia de programación de Trasvase de públicos, que consiste en conseguir aumentar la audiencia del canal con nuevos espectadores sin perder los que ya poseemos y que generalmente se produce a la finalización de nuestro programas cabecera, se utiliza promociones de estilo gráfico para anunciar cuando está acabando el contenido en emisión, superponiendo un rótulo o animación gráfica, lo que vendrá a continuación y así mantenemos a los espectadores cuando acabe el programa. La técnica de Stripping, que consiste en mantener en la misma franja horaria varios días seguidos a la semana un mismo contenido o género (Tira de Género), las promociones sirven de consolidación de la audiencia, ya no se busca en ningún momento informar puesto que el espectador ya tiene memorizado cuando es la emisión sino en fidelizarle ante ese contenido e intentar buscar nuevos espectadores, un claro ejemplo son las promociones de "Los Simpson" en Antena 3, también es aplicable estas promociones a la técnica de programación de Cimentación, donde consiste que las promos mantengan el nivel de audiencia que ya poseen ciertos contenidos, por ejemplo con promociones de los informativos de La 1 o Antena 3. La estrategia de programación de Stunting o Golpe de efecto, es cuando se programa un evento con gran atractivo para romper la rutina como puede ser los eventos deportivos, en este tipo las promociones suelen ser muy importantes puesto que debe anunciarse con suficiente fuerza para que surja efecto y suelen ser promociones generalmente con mayor presupuesto o tiempo de dedicación que el resto, ya que se supone que el canal ha realizado una gran inversión en este tipo de eventos.

Otras técnicas de programación como la Búsqueda de alternativas, Escalar por edades, Punta de lanza o Lead in, La hamaca o Hammocking, El mástil o Tent-poling, Duplex o back to back no afectan o no se ven afectadas por las promociones, por ello no entraremos en ellas. Todas las técnicas de programación en combinación con una acertada promoción pueden provocar las siguientes coyunturas programáticas como son los Periodos de máxima confusión, efecto pinza, efecto lazo, camas separadas, guerra total, líder por accidente, efecto arrastre y antesala, efecto domino; pero la coyuntura principal de programación a la que todo canal le gustaría verse afectado es la de Primera Opción, que se basa en la teoría de que el líder siempre tiene ventaja, no se utilizan promos para mejorar su efecto pero si para recalcar que lo son o bien afecta de manera directa a nuestras promociones puesto que si eres líder de audiencia tendrás mayor número de impactos y por lo tanto mayor será su efectividad. Todas estas técnicas están basadas y apoyadas en las entrevistas realizadas y en diversos autores (Orza, 2002: 67-76 y Contreras y Palacio, 2001: 169-215).

\section{Autopromociones desde el punto de vista de la comunicación publicitaria}

La comunicación publicitaria en las autopromociones posiblemente es la razón más importante de su existencia, innovación y mejora cualitativa y cuantitativa de hoy día. Las promociones intentan convencernos de lo que hay que ver y esto es fundamental entre la heterogeneidad de canales que existen actualmente, donde el espectador decide y es más exigente. Es una de las herramientas de marketing que poseen las tele- 
visiones para conquistar a la audiencia, "las televisiones en régimen de competencia han desplegado entre sus políticas de marketing la de la autopromoción. Una política en muchos casos agresiva, tendente a afirmarse con una imagen de marca lo suficientemente neta para que los espectadores seducidos acudan a ella en busca de la información y el entretenimiento que se les ofrece [...] Esta promoción de la cadena alcanza así el mismo objetivo que la publicidad. Es decir, vender. Con la diferencia de que lo que vende es su propia imagen o la de sus programas. O, lo que es lo mismo, la imagen del canal o emisora. Si bien puede ser de forma institucional o de alguna de las partes que componen la programación" (Cortés, 2001: 243).

Las autopromociones para J. Barroso "[...] actúan a modo de estrategia de autopotenciación y auto-publicidad del medio, cuyo propósito es vender más televisión y es a la vez un mecanismo de perpetuación: un producto se mantiene si atrae audiencia, si se vende, y por consiguiente, si atrae publicidad"(Barroso, 1996: 525).

La importancia de la autopromoción descansa en el hecho de que mediante ella una cadena selecciona las piezas de imagen que quiere grabar en la memoria de sus espectadores. No todos los programas se publicitan, únicamente aquellos que el canal considera que venderán una imagen acorde a sus pretensiones. Estos espacios no son meros recordatorios de la programación por venir, sino que se convierten en estandartes de los valores máximos de calidad de la oferta de cada canal; de los acontecimientos por los que el canal espera ser recordado; de la personalidad que aspira a comunicar. En esta línea, cada vez son más frecuentes un tipo de autopromoción, como son las autopromociones genéricas, que no anuncian un producto concreto, sino un genérico - deportes, informativos, o la totalidad de la cadena, teniendo como fin u objetivo mejorar y consolidar la imagen de marca o empresa en el espectador, además de favorecer la línea editorial de la propia cadena.

Como dice la Dra. González, "las autopromociones son piezas de continuidad que tienen un claro fin comercial para la promoción de un contenido de la cadena. Son piezas que se construyen mediante elementos audiovisuales que logren una relación directa con el contenido a promocionar (ya bien sea una serie, un programa, un informativo o una película) y, a su vez, mostrar al telespectador quién es la cadena que le oferta el contenido, es decir, cuál es la Identidad de la cadena emisora de la promoción" (González, 2008: 269). La elaboración de las autopromociones por parte de un canal implica la necesidad de diferenciar sus contenidos ante la audiencia presentándolos de una forma persuasiva para generar un cierto interés en su visión. El fin de este tipo de auto publicidad reside en "llamar la atención sobre lo que la televisión va a difundir"(Medina, 1998: 135). "Las autopromociones son elementos de carácter autónomo y compacto que recogen la información a destacar de los programas que la cadena va a emitir. Los diferentes espacios ofertados por el canal para la audiencia requieren una elaboración de carácter publicitario- persuasivo para generar expectación e índices de audiencia positivos para el canal. La oferta actual de las televisiones generalistas se caracteriza por tener contenidos muy similares entre sí, de ahí que se requiera un mayor uso estratégico de estas piezas de continuidad para generar un deseo y un primer contacto con el programa, al menos, para que se produzca su éxito." (González, 2008: 269) 
Y es que, como dice la Ley Graham de J.R. Graham (1993: 47, consultar bibliografía), "si no cuenta usted su historia, ¿por qué debería esperar que se conociera lo que vende?". Esa regla básica se aplica a las autopromos como iremos viendo más adelante. Para este autor, la autopromoción "es un concepto que comprende todas las actividades de la empresa acomete para dar a conocer su propia historia, como herramientas básicas a las que una empresa puede acudir para informar al mundo de sus productos, servicios y habilidades especiales. Si la campaña de autopromoción es acertada situará a la empresa donde quiere estar. Si es correcta la autopromoción situará a la empresa en la mente del cliente durante cincuenta y dos semanas al año, y las autopromociones no serán vistas como una intromisión sino que el propio cliente estará deseando recibir nuevas campañas para estar al tanto de nuestros productos"(Graham, 1993: 48). Esta definición de J.R. Graham es muy aproximada a lo que desean hacer las cadenas televisivas con sus promociones.

No hay que olvidar, que con la puesta en funcionamiento de la Televisión Digital Terrestre ha aumentado la demanda televisiva llegando a máximos históricos de consumo de horas de televisión por parte de los espectadores tal, y como demuestran los estudios de audiencia: "[...] Los 239 minutos consumidos por persona y día suponen un nuevo récord de consumo televisivo en España. Es el tercer año consecutivo de incrementos y la cifra supone 5 minutos más que el año anterior. Las nuevas tecnologías no parecen afectar al medio televisivo, sino más bien al contrario, retroalimentan al producto audiovisual" (Barlovento Comunicación, 2011). También cabe destacar la fragmentación paulatina y constante de la audiencia que cada vez más se divide entre la multitud de oferta de canales, cada vez más especializados en distintos contenidos, que se está produciendo: '[...] El conjunto de 'Temáticas con concesión TDT' llegan en 2011 al 24,6\% de cuota, casi la cuarta parte del mercado nacional. La fragmentación de audiencias no para de agudizarse; el 2011 ha sido el año en el que las tres grandes generalistas (La 1, Tele 5 y Antena 3 ) suman una menor cuota de pantalla: solo el 40,2\%" (Barlovento Comunicación, 2011). Por ello, las cadenas han tenido que replantearse la imagen que otorgan al espectador, y empezar a desmarcarse de sus competidores para mantener las cuotas ante un público cada vez más exigente. Una de las maneras de hacerlo es a través de los elementos denominados de continuidad, donde se encuentran las cortinillas y las autopromociones, estas últimas son las más utilizadas como herramienta publicitaria de la propia cadena donde los valores transmitidos, la identidad corporativa y todos los aspectos comunicativos que puedan contener estos formatos sirven para que el espectador tenga una reacción positiva respecto a este canal. Como viene a decir Cristina González Oñate: "En suma, veinte segundos de publicidad de autopromoción para que una cadena pueda transmitir una imagen nueva, llena de valores positivos para una sociedad que hoy en día cuestiona el propio medio"(González, 2008: 90).

Siempre que utilizamos las promociones como elementos publicitarios hay que tener en cuenta, a qué público te diriges, de nada sirve intentar hacer comunicación publicitaria sino diriges el mensaje a tu target. Esta teoría es bien conocida entre los departamentos de promociones y sus profesionales, que saben cuál es su target potencial. “[...] Se intenta llegar a todos los espectros posibles, pero ojo, tú tienes que contarás 
para un target en concreto, luego se virará más o menos, pero tienes tenerlo en cuenta"2.

El carácter de comunicación publicitaria que tienen las promociones y sobre todo la importancia de cara a conseguir audiencia han servido para que las promociones evolucionen y sean cada vez mayor la inversión en estas piezas. Para Valderrama, las autopromociones son: "Parte de la motivación para ver ese espacio surge de una intensa campaña promocional del canal que hace apetecible un primer contacto para el receptor" (Valderrama, 2005: web). Tal es la importancia de estas piezas que compiten por hacerse un hueco en las parrillas de las televisiones con la publicidad. Como dice Ángeles Moreno, “en España, desde la segunda mitad de la década de 1990, la autopromoción ha supuesto casi un cuarto de la publicidad emitida en el conjunto del medio televisión, llegando, incluso, a ocupar en algunos momentos más de la tercera parte de la publicidad total (Infoadex, 1996-2005)" (Moreno, 2007: 11-20).

Además existe una vertiente de la autopromoción dentro de los propios programas, donde intentan "vender" los formatos que emite ese canal a través de sus propios programas, para Alejandro Barranquero, "la autopublicidad explícita en formatos publicitarios declarados (house ads) se refuerza a base de alusiones implícitas y encubiertas insertas en toda la programación y que atañen tanto al propio medio como a otros del mismo grupo empresarial, a fin de crear sinergias - o autopublicidad intermedial-"(Barranquero, 2012: 252).

\section{Conclusiones}

La revolución y el paso de las autopromociones de elementos de continuidad y puramente informativos a elementos de comunicación publicitaria, se ha producido gracias a la competencia surgida a finales de los ochenta y sobre todo en los noventa. Se paso de una única cadena pública a un conglomerado de cadenas autonómicas y privadas nacionales, en pugna por los mismos espectadores dado el carácter generalista de todas. Para Valderrama: "En este mercado de competencia, las televisiones han dejado de ser un mero servicio para convertirse en auténticas marcas comerciales que necesitan dos pilares para su sustento: audiencia y publicidad. La autopromoción ya no sirve exclusivamente como elemento diferenciador o informativo sino que pasa a entrar de lleno en el campo de la publicidad" (Valderrama, 2005: web)

Aun así, es difícil separar ambos usos en cuanto a las autopromociones se refiere, tanto como labor de continuidad como publicitaria, las promociones juegan ambos papeles, en determinados momentos o posicionamiento en parrilla será más importante su labor de continuidad como hemos observado en TVE, aunque siempre sin dejar de lado su aspecto narrativo de convencer al espectador y absolutamente desde el punto de vista de la comunicación publicitaria. Estos dos usos son imprescindibles a la hora de abordar las autopromociones como nuevos contenidos docentes, ya que las autopromociones son clave para poder explicar elementos educativos universitarios en asignaturas tan variadas como la Programación y emisión en televisión, Marketing audiovisual, Reali-

${ }^{2}$ Entrevista a Joaquín Rodríguez Moldenhauer. Director del Departamento de Promociones de Antena 3. Realizada el 10 de Mayo de 2012. 
zación en televisión dentro del campo del Grado de Comunicación Audiovisual. Y dentro del campo del Grado de Publicidad puede servirnos de manera clara, la práctica y uso de estas piezas para desarrollar las habilidades creativas de los alumnos.

\section{Referencias bibliográficas}

BARLOVENTO COMUNICACIÓN (2011): Análisis Televisivo 2011. Madrid, 3 de enero de 2011.

BARROSO GARCÍA, Jaime (1996): Realización de los géneros televisivos. Madrid, Editorial Síntesis, Comunicación Audiovisual.

BARRANQUERO CARRETERO, Alejandro (2012): "Teoría de la autorreferencia mediática. Un balance crítico de los primeros estudios". Estudios sobre el Mensaje Periodístico, Vol. 18, $\mathrm{n}^{\mathrm{o}} 1$ (enero-junio). Madrid, Servicio de Publicaciones de la Editorial Complutense, pp. 243-258.

CONTRERAS, José Miguel y PALACIO, Manuel (2001): La programación en televisión. Madrid, Editorial Síntesis.

CORTÉS, José Ángel (2001): La estrategia de la seducción: la programación en la neotelevisión. Ediciones EUNSA. Universidad de Navarra.

GONZÁLEZ OÑATE, Cristina (2008): Nuevas estrategias de televisión. El desafio digital. Identidad, marca y continuidad televisiva. Madrid, Ciencias Sociales.

GRAHAM, John R. (1993): Marketing Magnético: la estrategia definitiva para atraer $y$ conservar clientes. Madrid, Diaz de Santos.

KOZLOFF, Sarah (1989): Invisible Storytellers: Voice-over narration in American fiction films, University of California Press.

MEDINA LABERÓN, Mercedes (1998): Valoración de la publicidad en los programas de televisión. Pamplona, Eunsa.

ORZA, Gustavo F. (2002): Programación televisiva: un modelo de análisis instrumental. Buenos Aires, La Crujía Ediciones.

MORENO FERNÁNDEZ, Ma de los Ángeles (2007): "El discurso de identidad de la televisión pública. La autopromoción de Televisión Española". Telos cuadernos de comunicación e innovación, $\mathrm{n}^{\mathrm{0}} 71$.

VALDERRAMA SANTOMÉ, Mónica (2005): «De la paleo a la neotv a través de la autopromoción y la identidad televisiva: El caso de TVG». Área abierta. http://revistas.ucm.es/portal/abrir.php?url=http://revistas.ucm.es/inf/15788393/articulo s/ARAB0505130004A.PDF. Web visitada el 09/10/2012.

WEINBERG, Alvin M. (1967): Impact of large-scale Science. The Federal Laboratories and Science Education. Science $\mathrm{n}^{\mathrm{o}} 136$.

\section{Javier PÉREZ SÁNCHEZ}

Universidad Europea de Madrid

javier.perez@uem.es

Profesor Asociado de la Universidad Europea de Madrid 